\title{
Do senior faculty members produce fewer research publications than their younger colleagues? Evidence from Ph.D. granting institutions in the United States
}

\author{
William E. Savage ${ }^{1}$ (D) Anthony J. Olejniczak ${ }^{1}$ (D)
}

Received: 23 April 2020 / Accepted: 17 March 2021 / Published online: 26 April 2021

(C) The Author(s) 2021

\begin{abstract}
The aging of the professoriate throughout the end of the twentieth century and the early years of the 2000's (both before and after the end of mandatory retirement in the United States, ca. 1994) has become a source of concern for some scholars and research administrators, who posit that the "greying" of the academy results in lower research activity and a decline in scientific advancement. Some published opinions concur that senior scholars' research programs do not keep pace with those of their younger colleagues, but little quantitative evidence has been presented to evaluate that claim. In this study, we quantify senior faculty publication activity in six broad fields, comparing their publication rates to their younger colleagues across four modes of knowledge dissemination: journal articles, conference proceedings, books, and book chapters. Career publication activity does not follow the "peak and decline" pattern described in earlier studies. In most fields, journal article publication rates do not decline substantively with age (and in some cases article publication rates are higher among senior scholars), conference proceeding publication rates tend to decline with age, while book and chapter publication rates increase markedly with age. Overall, senior scholars maintain publishing activity levels and tend to shift their focus to the development and evolution of ideas through the publication of longer-format works as books and book chapters.
\end{abstract}

Keywords Senior faculty $\cdot$ Research productivity $\cdot$ Aging professoriate $\cdot$ Publication activity $\cdot$ Career trajectory $\cdot$ Professorial age cohorts

\section{Introduction}

Throughout the decade ending in 2010, the proportion of faculty members aged 65 and older doubled in universities across the United States. Further, $75 \%$ of these senior scholars report that they plan to work beyond retirement age (Yakoboski, 2015). In an opinion article on faculty aging in the Washington Post, Zaretsky (2019) suggests the retirement

Anthony J. Olejniczak

aolejniczak@academicanalytics.com

1 Academic Analytics Research Center (AARC), 1985 W Henderson Road \#2159, Columbus, OH 43220, USA 
reluctance of baby boomer faculty members, those born between 1946 and 1964, has several undesirable consequences, including reduced research publication activity because senior scholars may produce fewer research outputs than their younger colleagues. This sentiment echoes earlier published opinions on faculty age demographics (e.g., Fendrich, 2014). The veracity of claims that senior scholars produce fewer research outputs is testable, as publication counts are readily quantifiable and the emergent field of scientometrics routinely makes use of such bibliometric data. Nonetheless, as Zaretsky (2019) notes, the state of senior faculty research productivity is unclear because few studies have documented senior faculty research outputs.

Prior to the end of mandatory retirement for professors in the United States in 1994, the perceived aging of the professoriate prompted several studies aimed at quantifying and understanding the role of senior faculty members at research institutions. A fundamental underlying question addressed by many of these studies is whether rates of scientific advancement could be maintained by an aging professoriate not required to vacate their positions. Some scholars reached ominous conclusions, suggesting that the scientific community would see a decline in advancement due to the growing number of aging scientists (e.g., Levin \& Stephan, 1989, 1991). These studies noted that over the course of a faculty member's career, one observes an early peak and gradual decline in the trajectory of journal article publications, which serve as a proxy for scientific productivity (e.g., Levin \& Stephan, 1989). However, three more recent studies (post-dating the end of mandatory retirement in the United States) suggest that a faculty member's age is not necessarily related to their overall scholarly productivity. These studies argue: (1) age is not a significant factor in continued research productivity (Bland et al., 2005); (2) there is no general age-related decline in cognitive ability (Stroebe, 2010); and, (3) the peak-and-decline model of journal article publication is a "remarkably inaccurate description" of the career trajectory of most faculty (Way et al., 2017).

Focusing on the use of scholarly publications as a proxy for productivity, several studies document potential motivating factors compelling faculty members to conduct and publish their research that are not necessarily related to the age of the individual. An econometric model, for instance, (Abramo et al., 2011; Levin \& Stephan, 1991) posits that faculty conduct research as an investment on future financial rewards (in the case of this model, the time horizon for future financial rewards is almost certainly modulated by a scholar's age). Other models emphasize "intrinsic motivation" (sensu Hardré et al., 2011, the personal satisfaction and enjoyment research activity provides the researcher) or combinations of both intrinsic and economic motivations (Rauber \& Ursprung, 2008). Still others posit that a combination of historical and contemporary factors, including past training and current relationships, are a major motivational factor in individual faculty research activity, and that academic origin and current academic affiliation act as strong predictors of research productivity (Fogarty, 2004; Fox, 1983; Long et al., 2009; Way et al., 2017). Perhaps the most comprehensive set of data assembled to explore research activity motivation is that of Bland et al. (2005), who tested eight individual, fifteen departmental, and four leadership characteristics for their relationship with faculty research activity. Notably, these studies all indicate a faculty member's age is not the sole determinant of research publication rates; rather, many factors appear to modulate research productivity.

Our review of the literature on productivity across professoriate age groups also revealed past studies exploring publication rates tend to focus on relatively small samples that are often limited to one or a few academic fields, a small number of institutions, or a small number of faculty members. Previous studies also incorporated a limited set of metrics to proxy research productivity, typically only journal article publications, though many 
other means of disseminating scholarship are available to researchers (e.g., conference proceedings, books, and chapters in edited volumes). Bonzi (1992), for example, examined the CVs of 411 faculty members at a single university and found professorial rank and field of study were two major determinants when looking at the level of faculty research activity. Likewise, questionnaire results from 465 faculty members in clinical and basic science departments at a single large research university were studied by Bland et al. (2005). Davis et al. (2001) limited their analysis to the discipline of Economics. They found journal article publication rates peak around tenure decisions, while book publication evinced a cyclic wave pattern throughout one's career. Kyvik (1990) studied tenured Norwegian scholars, identifying differences between fields of study, including multiple peaks in publication output at different ages among humanists, a steady rate of publication throughout the careers of social scientists, and a late-career decline in publications among faster-moving fields such as physics and biomedicine. Field-level differences were related by Kyvik to differences in the rate of knowledge production between disciplines (which he reports as slowest among the humanities and social sciences). In a later study, Kyvik and Olsen (2008) examined three age cohorts and found the productivity gap closed between older and younger faculty members among the Norwegian academy, concluding "While older staff published less than their younger colleagues two decades ago, no differences in productivity are found today."

Among studies incorporating larger datasets from a broader range of disciplines, Levin and Stephan (1989) tracked journal article publications over two years $(1978,1979)$ for the cohort identified in the 1977 National Research Council's Survey of Doctoral Recipients. The study extended across four fields: biochemistry, physics, earth science, and plant and animal physiology. Levin and Stephan's results showed an age-publishing relationship, typified by a publishing peak and gradual decline, existed across all fields. In the physical sciences, peak output occurred among the youngest faculty. In the life sciences, peak output occurred among scientists well into their career. In a later study (Levin \& Stephan, 1991), they examined 18,909 faculty members in solid state/condensed matter physics, particle physics, atomic and molecular physics, oceanography, geophysics and geology. Again, they concluded that despite some differences between fields, scientists become less productive as they age. Bonaccorsi and Daraio (2003) studied one year of journal articles authored by Italian National Research Council scholars, also concluding that scientific productivity declines with increased age. Conversely, Abramo et al. (Abramo et al., 2011) found that senior faculty members (in this study defined as full professor rank) outproduced other ranks in terms of publications and citations in a study of 30,677 faculty members at Italian universities between 2004 and 2008 in nine "hard sciences" fields.

More recently, senior faculty publication activity was studied in the field of Computer Science, including a large sample of faculty members from 205 Ph.D.-granting Computer Science departments in the United States for the academic year 2011-2012 (Way et al., 2017). Way et al.'s (2017) analysis examined the life-cycle publishing peak-and-decline model and found that only about $20 \%$ percent of computer science faculty's career publishing pattern follows such a trajectory. Rather, they observed the overall rate of publication has been increasing in recent decades, and higher institutional prestige is an important correlate of increased publication activity for an individual scholar.

The relationship between age and scholarly publication productivity depends on several factors, including the field explored by the individuals studied, the date a study sample was extracted (in light of overall increased publication rates in the last 40 years), and the choice of metrics used to quantify productivity. The sometimes-conflicting results of past studies may be due, in part, to samples limited by geography, field, timeframe studied, and 
relatively narrow definitions of "productivity." Here, we aim to present and analyze what we believe is the largest sample assembled for the purposes of exploring the relative contributions of senior scholars to the overall research output at universities in the United States. We quantified the publishing activity of three age cohorts in the professoriate at U.S. Ph.D. granting institutions (early career scholars, mid-career scholars, and senior scholars) across a wide range of fields and through four modes of knowledge dissemination (journal articles, conference proceedings, books, and chapters in edited volumes). Specifically, we explore the following research questions:

1. Do senior faculty produce disproportionately more or fewer research outputs than their younger colleagues relative to their proportion of the total population in the field of study? We define four types of scholarly output: journal articles, conference proceedings, books, and chapters in edited volumes.

2. Do most senior scholars participate equally in the production of publications by their age cohort, or do a small number of faculty produce most of the publications? For example, it may be the case that the total number of book chapters produced is equal across age cohorts, but in one cohort scholars have each published a small number of book chapters, while in another cohort a small percentage of individuals have produced large quantities of book chapters (while the remaining individuals have produced few or none).

3. Does the commonly cited "early peak and gradual decline" model characterize research publication activity across fields of study and across scholarly publication types, with publication output slowly decreasing post-tenure?

\section{Data and methods}

We extracted the publication histories and academic age data for 167,299 faculty members with a professorial rank of Professor, Associate Professor, or Assistant Professor from the Academic Analytics commercial database (Academic Analytics, LLC; database version AAD2018-1391, representing the Fall 2018-Spring 2019 academic year. The Academic Analytics database contains tenure-track faculty from $380 \mathrm{Ph}$.D.-granting university in the United States. The complete list of universities we included is available at https://osf.io/ 76urq). According to the National Center for Educational Statistics (NCES 2019), there were 1,542,613 faculty classified as "instruction/research/public service" employed by all United States degree-granting post-secondary institutions in the Fall 2018 semester; our sample of faculty from Ph.D. granting institutions thus constituted about $10.8 \%$ of all faculty in the United States. Each of the faculty members whose information we extracted is affiliated with one or more academic departments at one of 380 United States Ph.D. granting research institutions. Each of the 9,015 academic departments is classified into one or more of six broad fields of study:

1. Biological and Biomedical Sciences

2. Business

3. Engineering

4. Humanities

5. Physical and Mathematical Sciences

6. Social and Behavioral Sciences 
The six fields are based on NCES 2-digit CIP codes (NCES 2013); a complete list of departments and their classification into fields is available as supplemental materials (https://osf.io/76urq/). The Academic Analytics database also contains the year and type of terminal degree for each faculty member (typically the Ph.D., but sometimes M.F.A., M.B.A., etc.), from which a proxy for an individual's age may be calculated. Hereafter, we define "academic age" as the year our faculty lists were assembled (calendar year 2018) minus the year of terminal degree. For example, a scholar who completed their Ph.D. in 1995 has an academic age of $2018-1995=23$ years. We assigned each scholar to one of three age cohorts:

1. Early career scholars, Academic Age 1-10 years.

2. Mid-career scholars, Academic Age 11-30 years.

3. Senior scholars, Academic Age 31 years and above.

The faculty members in our study are all tenured or tenure track, most have a rank of "Professor," "Associate Professor," or "Assistant Professor." The number of faculty of each professorial rank in each broad field is available at https://osf.io/76urq/.

For each faculty member, we also extracted the total number of scholarly research outputs authored (including co-authorships) over the five-year period spanning 2014-2018 (inclusive). Specifically, we extracted the following for each faculty member:

1. The number of journal articles authored in a collection of 28,347 scholarly journals.

2. The total number of conference proceedings published from a collection of 9369 conferences.

3. The total number of books published.

4. The total number of book chapters in edited volumes published.

For the overall dataset and for each of the six fields, we calculated the total number and the proportion of each type of scholarly output produced by each of the age cohorts. We also calculated the difference between the percent of the population that is a particular age cohort and the percent of each type of scholarly output produced by that age cohort to identify areas where one cohort may be producing more or fewer outputs than expected relative to their percent of the population. For example, if senior scholars represent $30 \%$ of the faculty members in a field of study and they author $35 \%$ of the journal articles in that field, then senior scholars have produced 35\% -30\%=5\% more journal articles than expected.

For each scholarly publication type in each field, we tested for significant differences in the quantity of outputs published by the three age cohorts. We employed nonparametric Kruskal-Wallis tests to check for group differences (parametric tests for differences in group means such as ANOVA assume normally distributed data, but our data are left-skewed, with many scholars in each age cohort showing zero publications for each type of output). Post-hoc comparisons to identify specific group differences when the Kruskal-Wallis test was significant were performed via the Dunn test.

We also explored differences in the proportion of each age cohort that participates in the publication of each type of scholarly output (e.g., two age cohorts may have produced the same number of book chapters, but in one case the chapters may have been authored by many scholars each producing a few chapters, while in another cohort a small number of scholars may have written a majority of the chapters). To explore the rate of participation by age cohorts for each scholarly output type, field, and age cohort, the percent of scholars 
who have produced at least one of that type of output was calculated. Finally, to explore the "early peak and gradual decline" model of career publication trends we created plots showing the mean number of scholarly outputs by academic age for each type of publication and for each field, from zero to 65 years since terminal degree.

\section{Results and discussion}

The population of each field and for the entire dataset is given by age cohort in Table 1, and the counts of each type of scholarly output by age cohort and by field are given as Table 2 . Over the entire dataset, $22 \%$ of scholars are early career, $52 \%$ are mid-career, and $26 \%$ are senior scholars. Although there is broad agreement across fields in terms of the percent of faculty members in each age cohort, Biological and Biomedical Sciences is unusual among the fields studied in that only $13 \%$ of the population are early career scholars, well below the 20-32\% range for the other fields. The relative dearth of early career researchers in Biological and Biomedical Sciences may reflect the importance of post-doctoral positions in those disciplines. The Academic Analytics database does not capture post-doctoral researchers, only tenured and tenure-track faculty members. Hence, this limitation may result in undercounting of the overall research activity of this age cohort in this field. The lower percentage of early career scholars in this field is likely responsible for Biological and Biomedical Sciences also showing the greatest percentage of senior scholars (31\%) among the fields we explored.

The number of journal articles authored by each age cohort is given in Table 3, as are the percent of all articles that age cohort produced within each field and the difference from the expected number of articles produced by that age cohort in that field. Senior scholars publish between $3 \%$ fewer and $2 \%$ more than expected journal articles, depending on the field of study. In two STEM fields (Biological and Biomedical Sciences and Physical and Mathematical Sciences), senior scholars publish slightly more journal articles than expected given their proportion of the population. All other fields show a slight drop in journal article production among senior scholars. Kruskal-Wallis tests (Table 4) reveal that every field is characterized by significant differences in the publication of journal articles across age cohorts, and post-hoc tests show that age cohort differences are significant in all but one case: early career and mid-career scholars in Social and Behavioral Sciences do not publish significantly different numbers of journal articles, on average.

Plots showing the mean number of journal article publications by academic age appear as the top panels in Figs. 1, 2, 3, 4, 5 and 6. In three fields (Business, Humanities, and Social and Behavioral Sciences), a small peak in average journal articles published appears within the first 10 years followed by a slightly declining trajectory thereafter. This pattern does not describe STEM fields. In Physical and Mathematical Sciences and Biological and Biomedical Sciences, for example, journal article output increases from zero years since terminal degree to approximately 12-15 years since terminal degree, and then remains relatively stable throughout one's career. Since our observations are being made at the broad field level, direct comparisons to the trajectory of computer science faculty career publication trends studied by Way et al. (2017) are not possible. However, we concur with their finding that the narrative of early growth in publication rates followed by a peak and a gradual decline does not universally describe career publication patterns. Plotting averages for each academic age (Figs. 1, 2, 3, 4, 5 and 6) may mask differences between individuals in publication trends over time, and grouping scholars into broad fields may also 


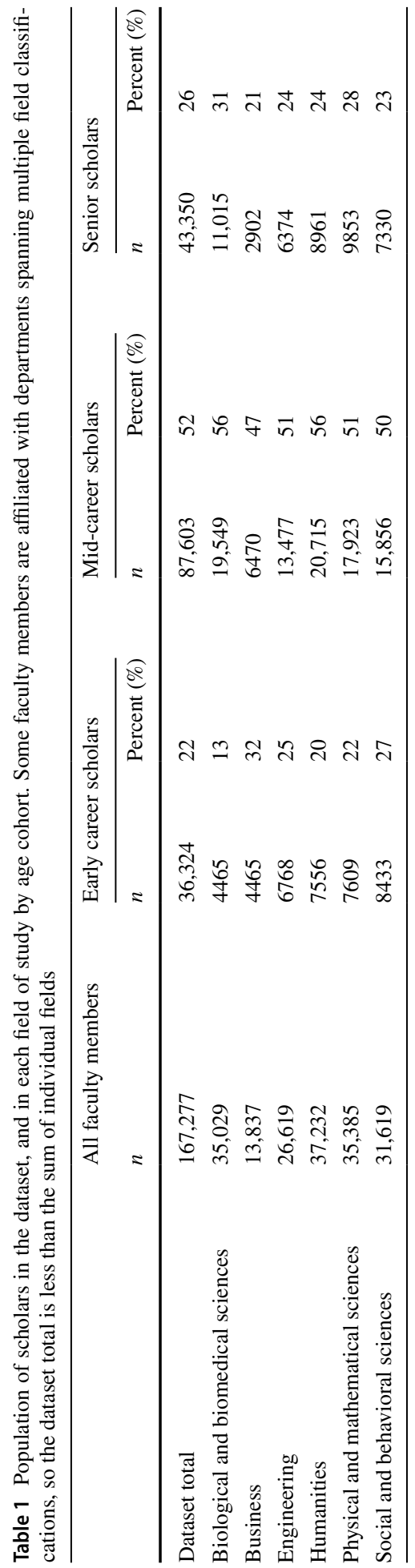




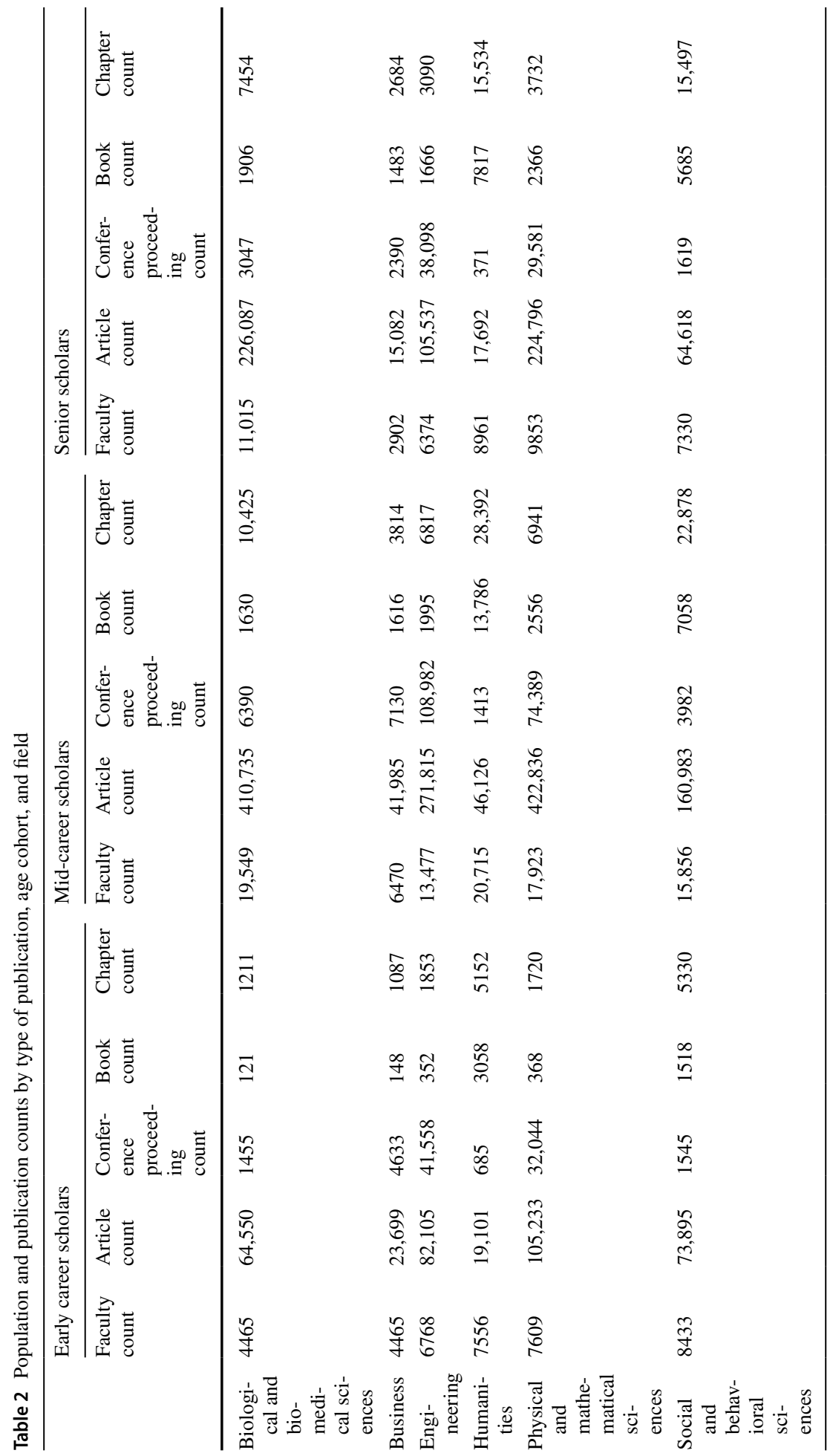




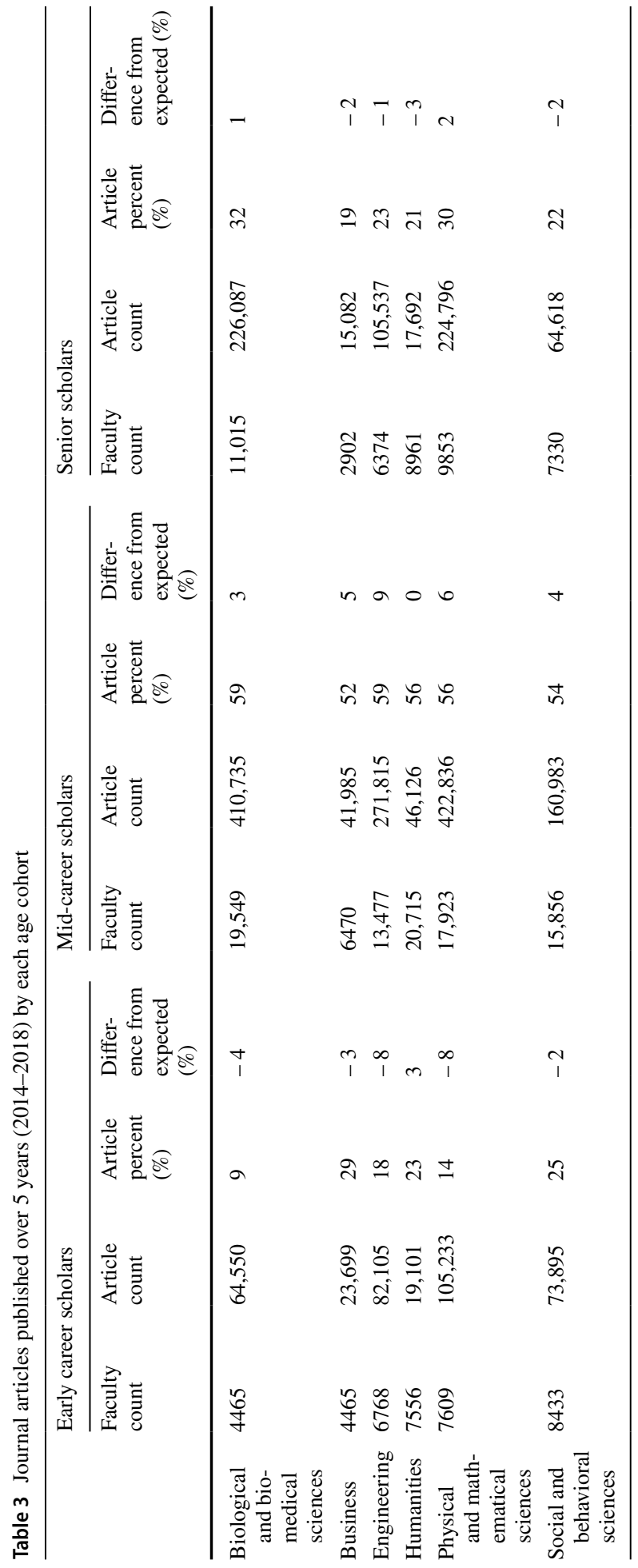


Table 4 Kruskal-Wallis and Dunn post-hoc test results comparing journal articles published across age cohorts

\begin{tabular}{|c|c|c|c|c|}
\hline & \multirow[t]{2}{*}{ Kruskal-Wallis T } & \multicolumn{3}{|c|}{ Post-hoc comparisons } \\
\hline & & $\begin{array}{l}\text { Early career vs } \\
\text { Mid-career }\end{array}$ & $\begin{array}{l}\text { Early career } \\
\text { vs senior }\end{array}$ & $\begin{array}{l}\text { Mid- } \\
\text { career vs } \\
\text { senior }\end{array}$ \\
\hline Biological and biomedical sciences & $399 * * *$ & $* * *$ & $* * *$ & $* * *$ \\
\hline Business & $297 * * *$ & $* * *$ & $* * *$ & $* * *$ \\
\hline Engineering & $828 * * *$ & $* * *$ & $*$ & $* * *$ \\
\hline Humanities & $549 * * *$ & $* * *$ & $* * *$ & $* * *$ \\
\hline Physical and mathematical sciences & $610 * * *$ & $* * *$ & $* *$ & $* * *$ \\
\hline Social and behavioral sciences & $348 * * *$ & & $* * *$ & $* * *$ \\
\hline
\end{tabular}

$* p<0.05 ; * * p<0.01 ; * * * p<0.001$

mask subfield variation in publication patterns (e.g., different trajectories may describe economics and anthropology, both of which are classified here as "Social and Behavioral Sciences"). Nonetheless, our data show that comparisons of the three age cohorts we defined do not support the peak-and-decline model. Rather, among STEM fields which are the most well-studied areas by previous researchers (Abramo et al., 2011; Bonaccorsi \& Daraio, 2003; Way et al., 2017), we find the senior scholar age cohort publishes more journal articles than expected (Table 3). Combined with the plots in Figs. 1, 2, 3, 4, 5 and 6, these data may be taken as a rejection of the peak-and-decline model of journal article publication activity in the fields we studied, although early career peaks do characterize the non-STEM fields.

Conference proceedings are a primary vehicle for the dissemination of peer reviewed scholarly work in a specific group of disciplines. Fast-paced academic fields such as Computer Science and many Engineering subfields rely on conferences for quicker peer review cycles and more predictable publication timing than many scholarly journals can offer. The number of conference proceedings published by each age cohort is given in Table 5. The difference from expected results for conference proceeding publications among the senior scholar cohort ranges from -1 (Social and Behavioral Sciences) to $-9 \%$ (Humanities). In all fields, the senior scholar cohort publishes fewer than expected conference proceedings. Further, the difference between mid-career scholars and senior scholars in terms of conference proceedings published is significant in all but two fields (Humanities and Social and Behavioral Sciences). These two fields show the lowest number of conference proceedings published overall. Hence, this type of publication may not be a good measure of scholarly activity in these fields. Nonetheless, a clear pattern showing fewer conference proceedings published by senior scholars across all disciplines is apparent. This trend is made clear by the plots in the second panels of Figs. 1, 2, 3, 4, 5 and 6. In the two fields with the most conference proceeding activity, Engineering and Physical and Mathematical Sciences, all age cohort comparisons show significant differences from one another (Table 6). Career trajectory plots (Figs. 3 and 5) show a gradual but clear decline in conference proceeding publication rate among the senior scholar cohort.

Data describing book publication activity by academic age cohorts is given in Table 7 . Book publication data reveal a clear pattern where senior scholars publish many more books than expected (ranging from $8 \%$ in Humanities to $25 \%$ more than expected in 
Mean Journal

Articles Published

Mean Conference Proceedings Published

\section{Mean Books \\ Published}

\section{Mean Chapters}

Published
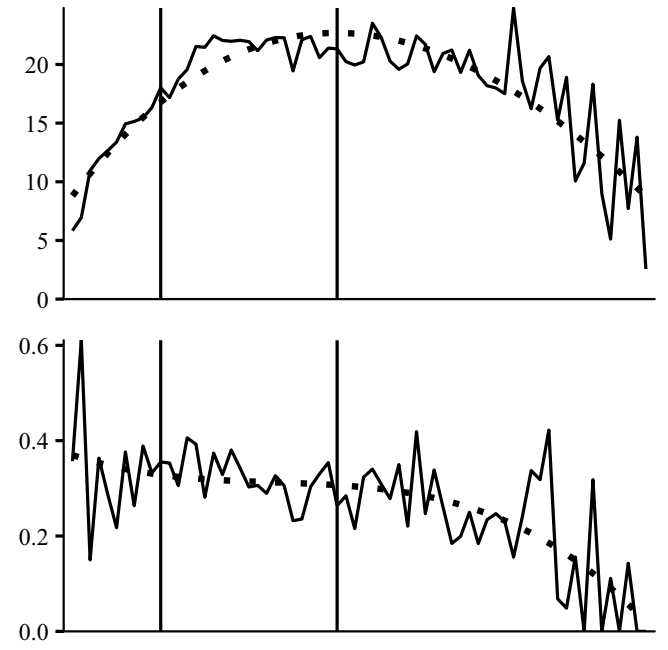

Faculty

Count
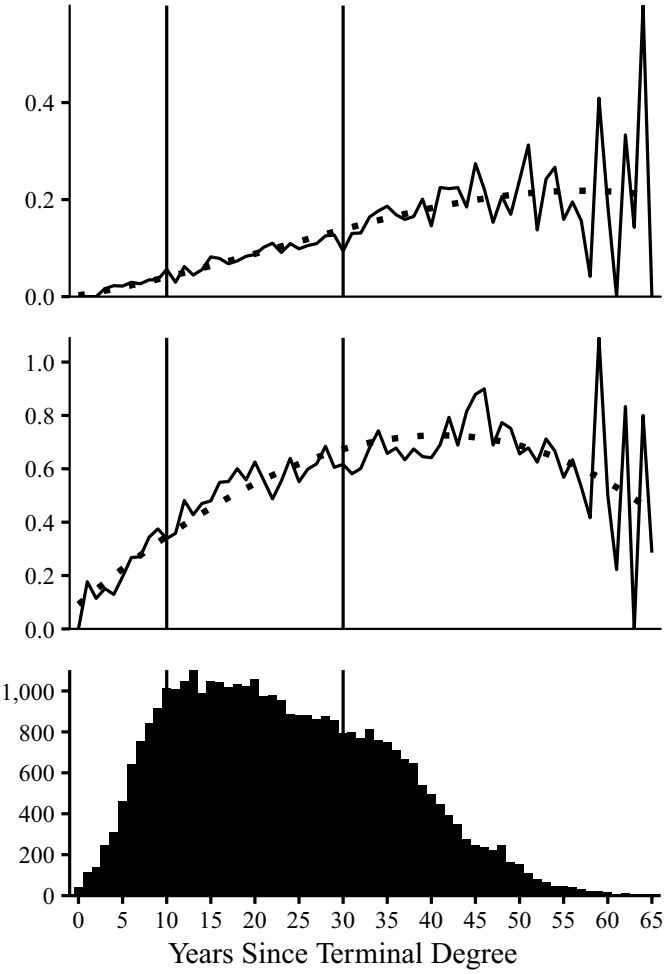

Biological and Biomedical Sciences

Fig. 1 The mean number of scholarly outputs by academic age (years since terminal degree) in the field Biological and Biomedical Science, truncated at 65 years from terminal degree. The histogram at the bottom shows the total population of scholars in this field by years since terminal degree. Vertical lines at 10 and 30 years demarcate the three age cohorts we identified. Dotted line is a lowess smoothed line to facilitate interpretation of the overall trend 
Mean Journal Articles Published

Mean Conference Proceedings Published

\section{Mean Books \\ Published}

\section{Mean Chapters} Published

Faculty Count
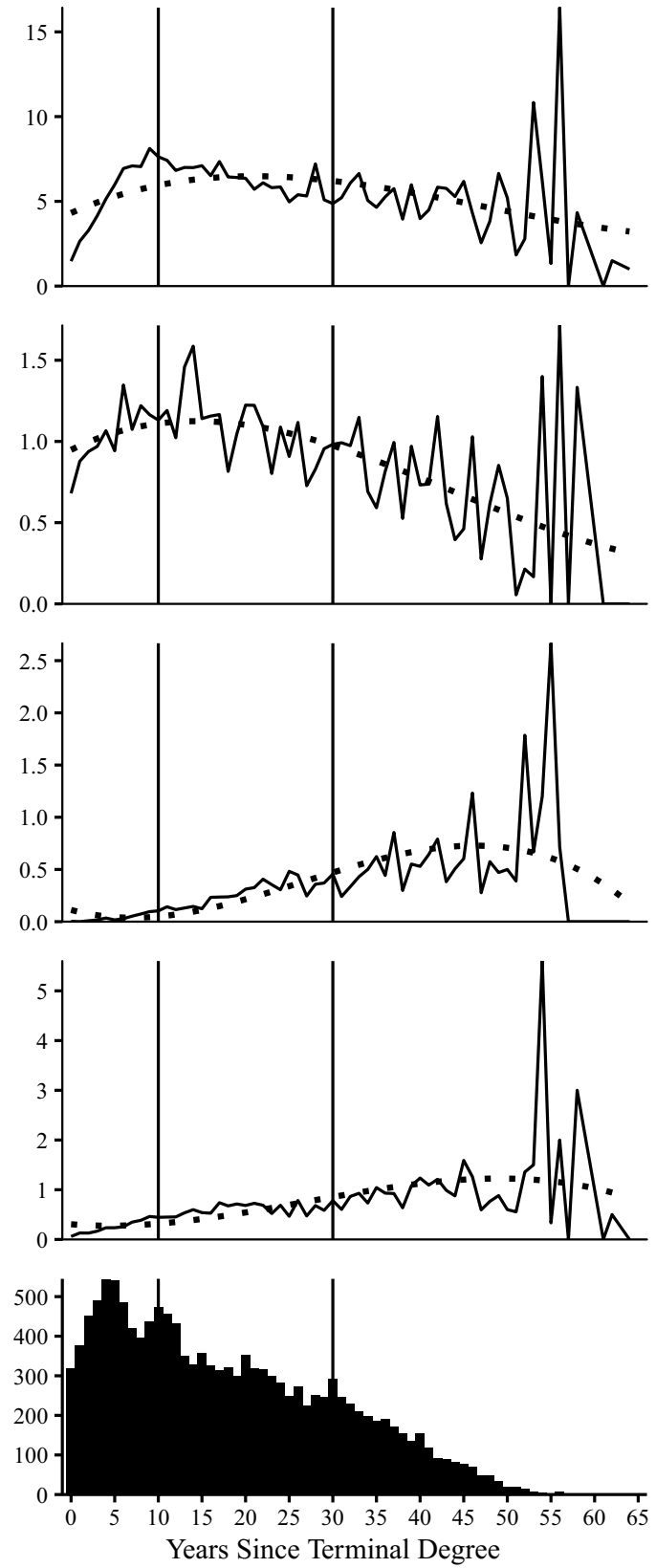

Business

Fig. 2 The mean number of scholarly outputs by academic age (years since terminal degree) in the field Business, truncated at 65 years from terminal degree. The histogram at the bottom shows the total population of scholars in this field by years since terminal degree (groups with fewer than five scholars have been omitted). Vertical lines at 10 and 30 years demarcate the three age cohorts we identified. Dotted line is a lowess smoothed line to facilitate interpretation of the overall trend 
Mean Journal Articles Published

Mean Conference Proceedings Published

\section{Mean Books \\ Published}

\section{Mean Chapters Published}
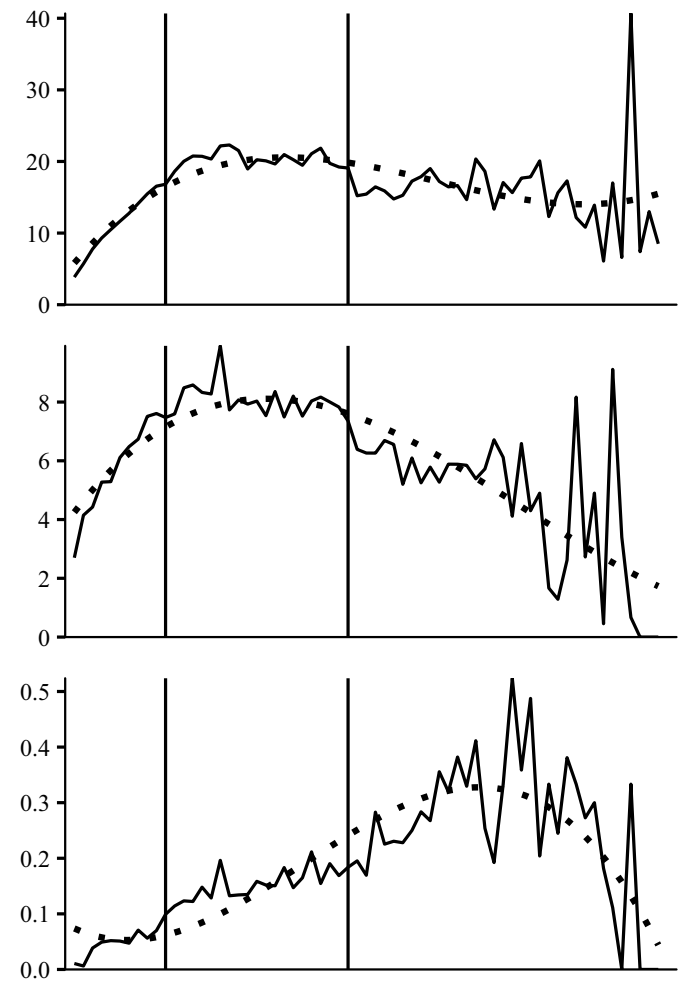

Faculty

Count

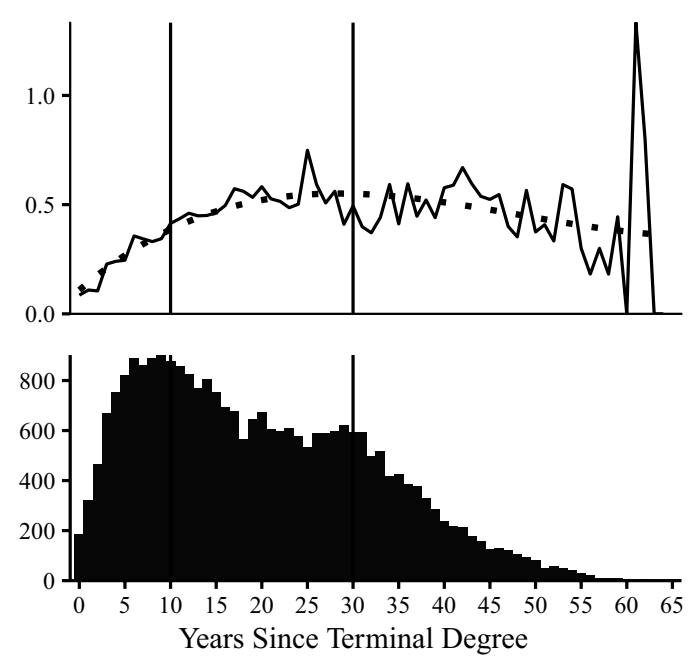

Engineering

Fig. 3 The mean number of scholarly outputs by academic age (years since terminal degree) in the field Engineering, truncated at 65 years from terminal degree. The histogram at the bottom shows the total population of scholars in this field by years since terminal degree (groups with fewer than five scholars have been omitted). Vertical lines at 10 and 30 years demarcate the three age cohorts we identified. Dotted line is a lowess smoothed line to facilitate interpretation of the overall trend 
Mean Journal Articles Published

Mean Conference Proceedings Published

\section{Mean Books Published}

Mean Chapters Published

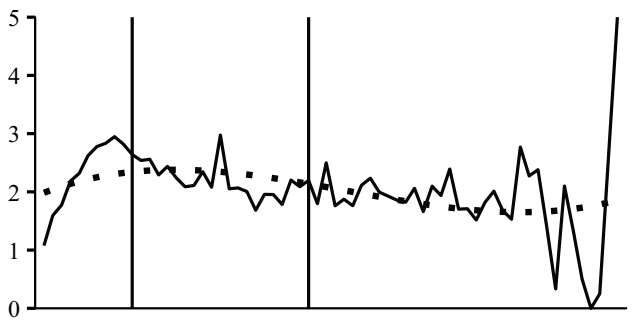

Faculty Count
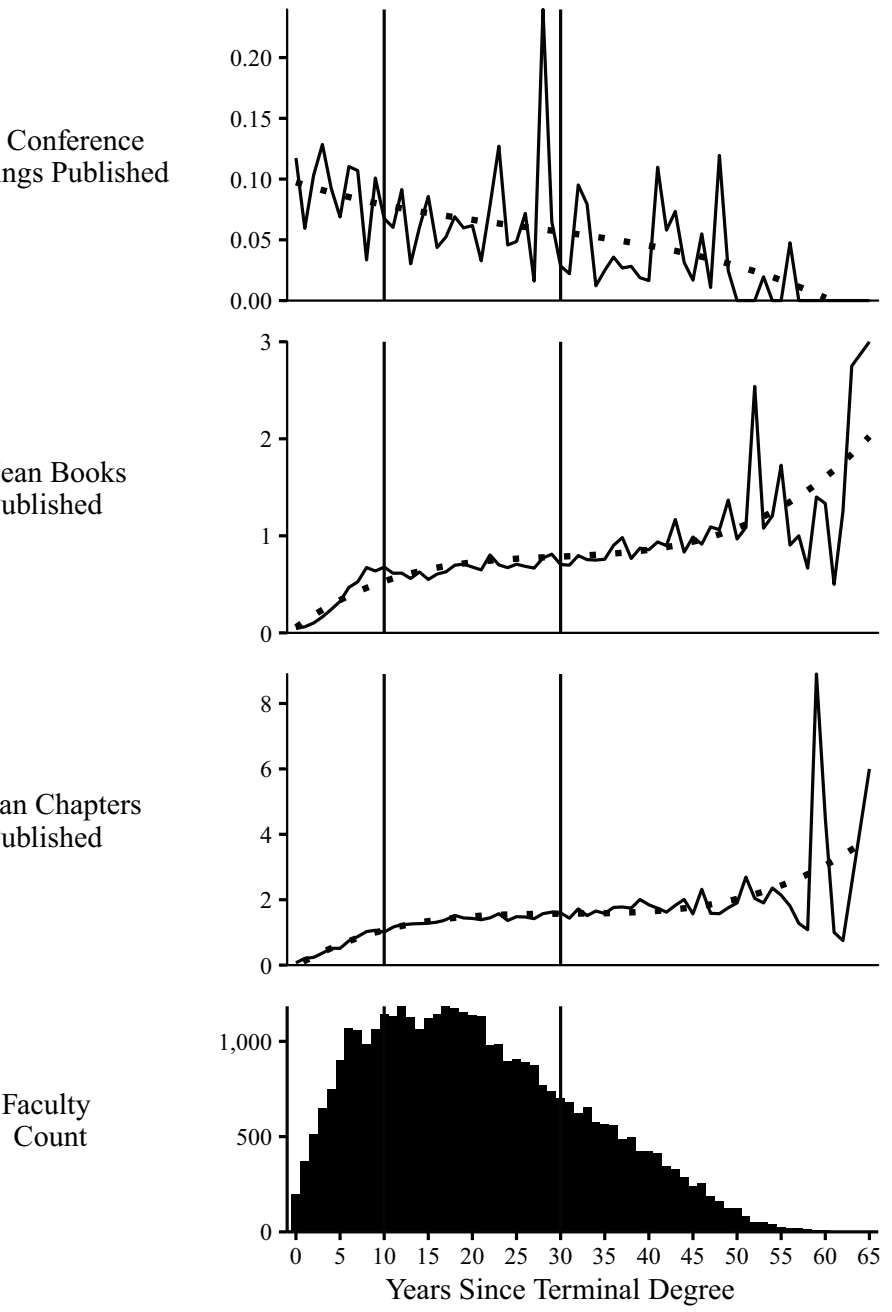

Humanities

Fig. 4 The mean number of scholarly outputs by academic age (years since terminal degree) in the field Humanities, truncated at 65 years from terminal degree. The histogram at the bottom shows the total population of scholars in this field by years since terminal degree (groups with fewer than five scholars have been omitted). Vertical lines at 10 and 30 years demarcate the three age cohorts we identified. Dotted line is a lowess smoothed line to facilitate interpretation of the overall trend 
Mean Journal Articles Published

Mean Conference Proceedings Published

\section{Mean Books Published}

\section{Mean Chapters} Published

Faculty Count
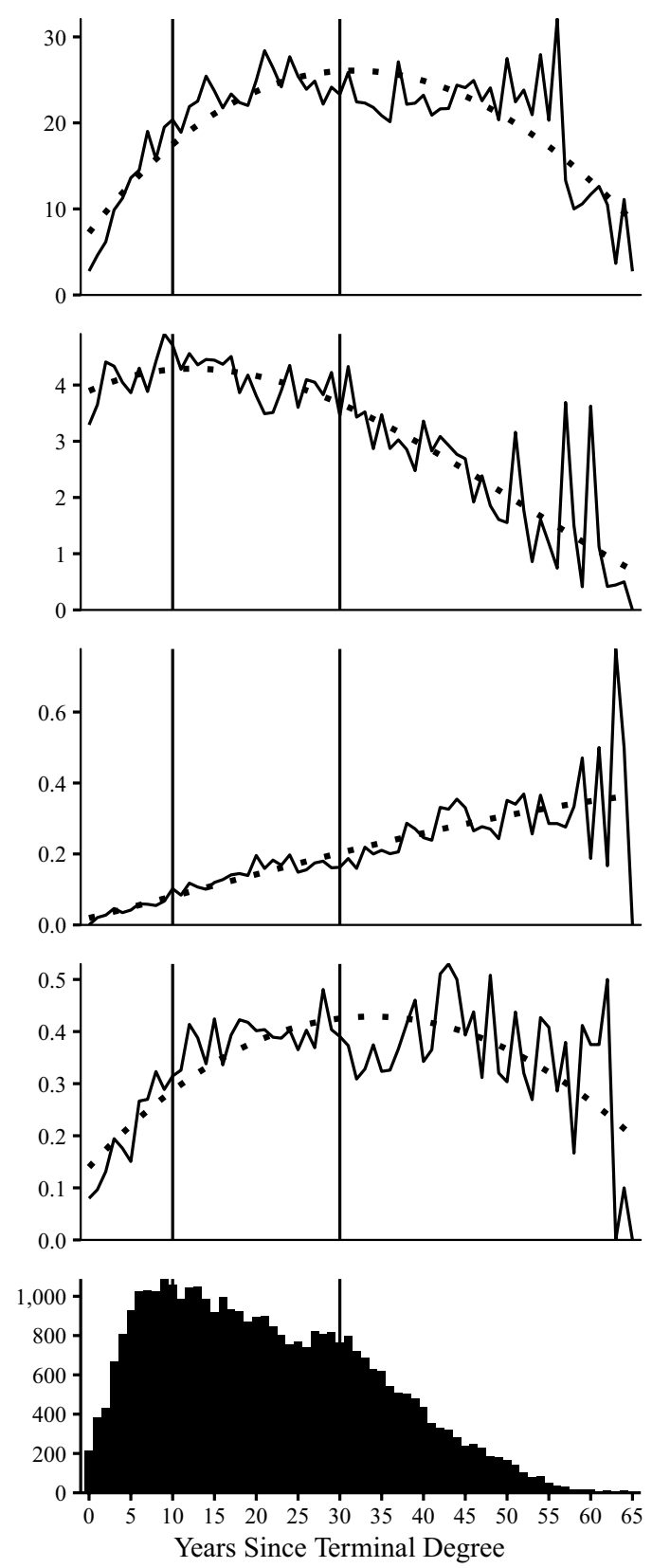

Physical and Mathematical Sciences

Fig. 5 The mean number of scholarly outputs by academic age (years since terminal degree) in the field Physical and Mathematical Sciences., truncated at 65 years from terminal degree. The histogram at the bottom shows the total population of scholars in this field by years since terminal degree (groups with fewer than five scholars have been omitted). Vertical lines at 10 and 30 years demarcate the three age cohorts we identified. Dotted line is a lowess smoothed line to facilitate interpretation of the overall trend 
Mean Journal Articles Published

Mean Conference Proceedings Published

Mean Books
Published

\section{Mean Chapters}

Published
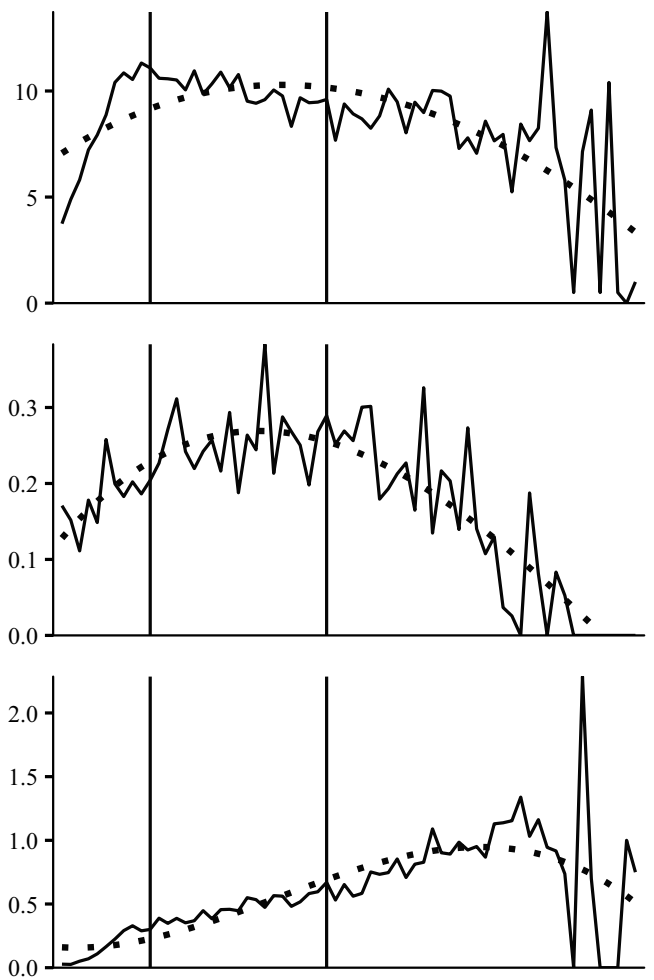

Faculty

Count
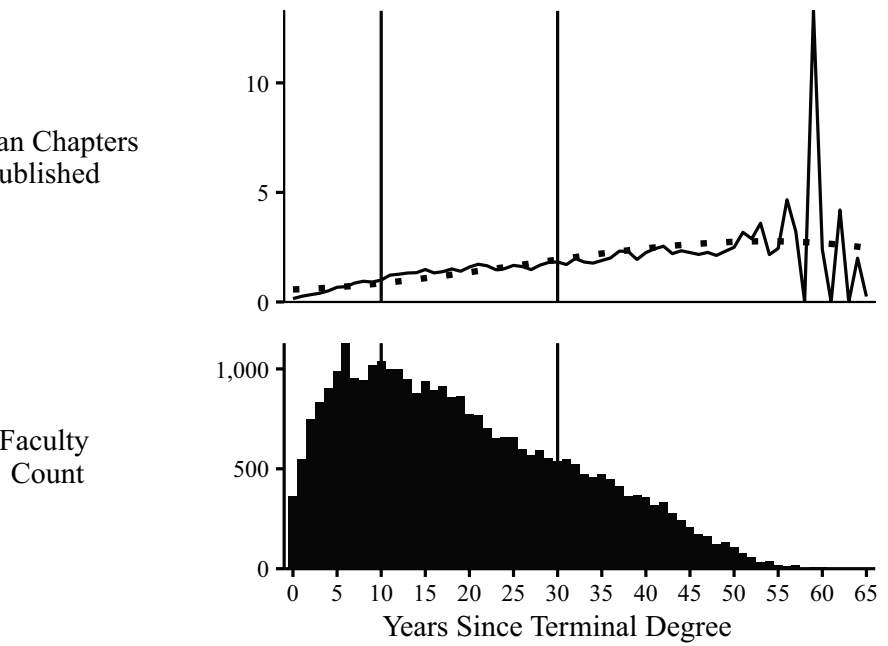

Social and Behavioral Sciences

Fig. 6 The mean number of scholarly outputs by academic age (years since terminal degree) in the field Social and Behavioral Sciences, truncated at 65 years from terminal degree. The histogram at the bottom shows the total population of scholars in this field by years since terminal degree (groups with fewer than five scholars have been omitted). Vertical lines at 10 and 30 years demarcate the three age cohorts we identified. Dotted line is a lowess smoothed line to facilitate interpretation of the overall trend 


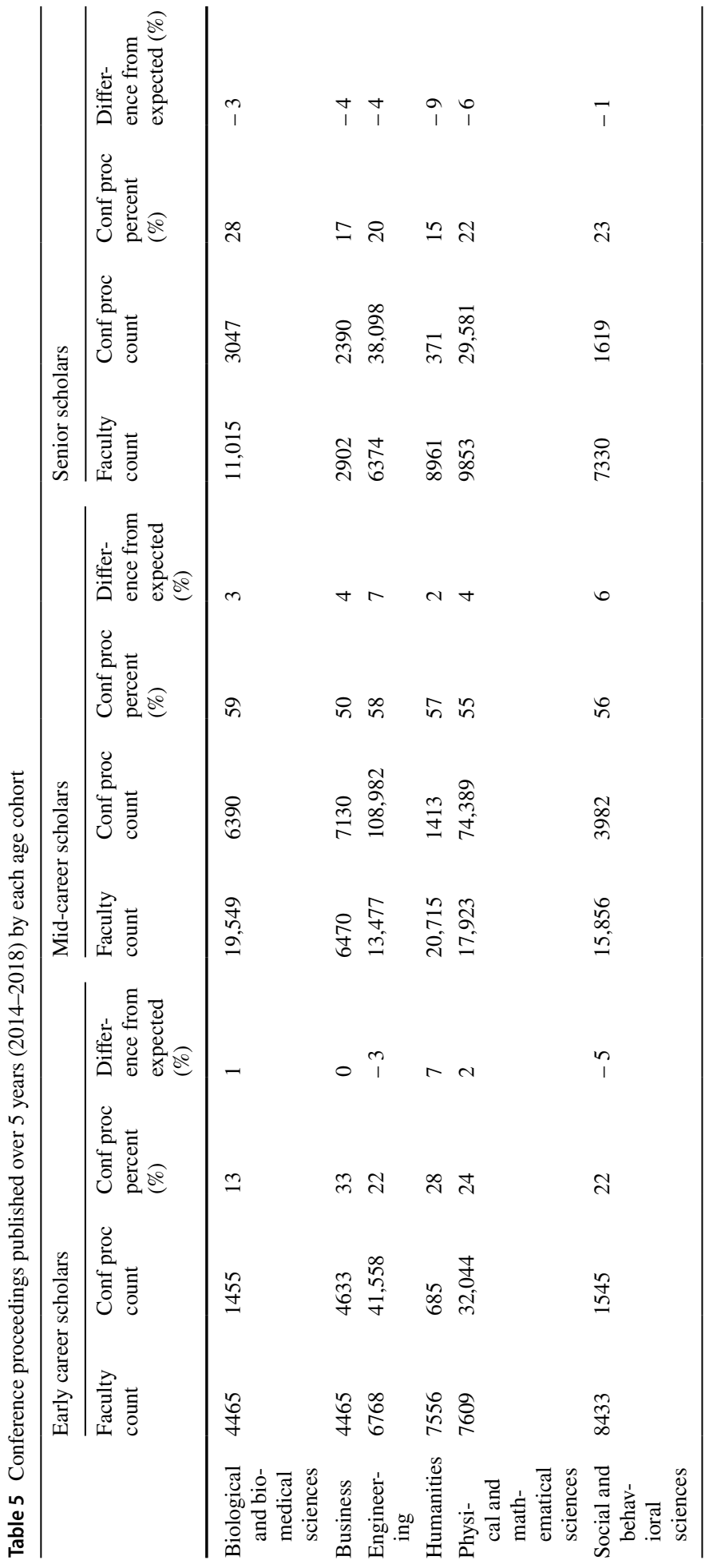


Table 6 Kruskal-Wallis and Dunn post-hoc test results comparing conference proceedings published across age cohorts

\begin{tabular}{|c|c|c|c|c|}
\hline & \multirow[t]{2}{*}{ Kruskal-Wallis T } & \multicolumn{3}{|c|}{ Post-hoc comparisons } \\
\hline & & $\begin{array}{l}\text { Early career vs } \\
\text { Mid-career }\end{array}$ & $\begin{array}{l}\text { Early career } \\
\text { vs senior }\end{array}$ & $\begin{array}{l}\text { Mid- } \\
\text { career vs } \\
\text { senior }\end{array}$ \\
\hline Biological and biomedical sciences & $11.6^{* *}$ & & & $* *$ \\
\hline Business & $48.5^{* * *}$ & & $* * *$ & $* * *$ \\
\hline Engineering & $246 * * *$ & $* * *$ & $* * *$ & $* * *$ \\
\hline Humanities & $40 * * *$ & $* * *$ & $* * *$ & \\
\hline Physical and mathematical sciences & $249 * * *$ & $* * *$ & $* * *$ & $* * *$ \\
\hline Social and behavioral sciences & $13.9 * * *$ & $* * *$ & & \\
\hline
\end{tabular}

$* p<0.05 ; * * p<0.01 ; * * * p<0.001$

Business), while early career scholars publish many fewer books than expected (ranging from $-8 \%$ in Humanities to $-28 \%$ in Business). All inter-group comparisons in book publication rates were significant (Table 8), pointing to a pattern that appears to be universal. Having launched their careers through journal article and conference proceeding publications, scholars increasingly turn to longer-term projects suitable for publication books as a means to disseminate their research. Figures 1, 2, 3, 4, 5 and 6 confirm this trajectory from fewer to more books published throughout one's career. This pattern describes all six fields studied.

In fields where book publications are most common (Humanities and many subfields within Social and Behavioral Sciences), books are of critical importance to establishing one's career and are an expected part of one's research program. In these fields, our data reveal a substantial number of early career faculty are publishing books. Moreover, the number of books published increases for mid-career faculty. This increase continues through the transition from mid-career to senior scholar. A variant of this pattern is seen in Business, where early career scholars publish very few books, while book publications increase substantially among mid-career and senior scholars (Fig. 2). Among STEM fields, both early and mid-career scholar cohorts publish fewer than expected books. In contrast, book publishing in these fields is dominated by senior scholars. In the three STEM fields we examined, book publication activity increases over the course of one's career as journal article and conference proceeding publications gradually decrease, suggesting a change of focus on the means of knowledge dissemination as STEM scholars age. Books in STEM offer an opportunity to synthesize or review several years of research in a specific area in addition to producing new knowledge. Books require a greater time investment to produce than journal articles or conference proceedings. The production of books by senior STEM scholars likely represents an important service to their fields that their younger colleagues may not be able to make, or which may not be rewarded.

Chapters published in edited volumes are an important method of research dissemination in many fields. Unlike journal articles, conference proceedings, and books, many chapters are solicited by the book's academic editors. Often, edited volumes result from conferences where some or all conference participants are invited to submit a chapter to a themed volume. Our data describing chapter publications across age cohorts (Table 9) show senior scholars produce more chapters than expected in all fields (ranging from $2 \%$ 


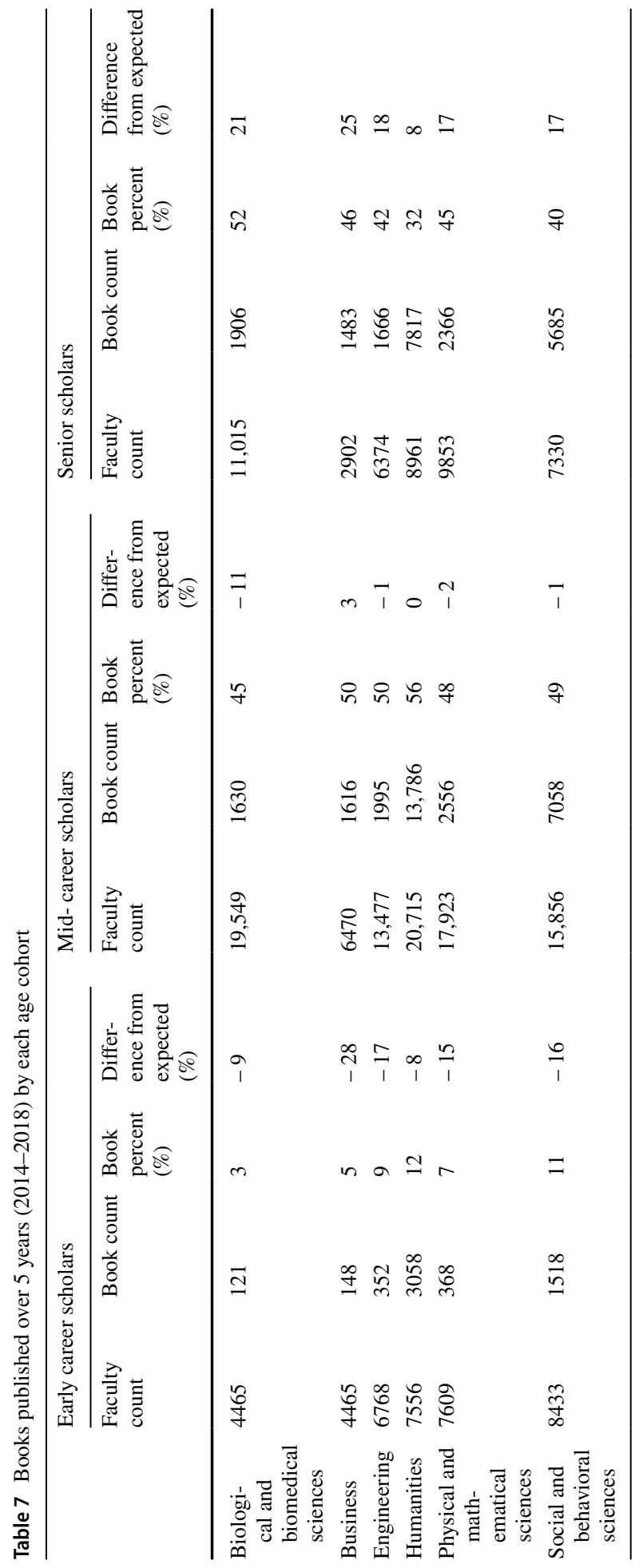


Table 8 Kruskal-Wallis and Dunn post-hoc test results comparing books published across age cohorts

\begin{tabular}{|c|c|c|c|c|}
\hline & \multirow[t]{2}{*}{ Kruskal-Wallis T } & \multicolumn{3}{|c|}{ Post-hoc comparisons } \\
\hline & & $\begin{array}{l}\text { Early career vs } \\
\text { Mid-career }\end{array}$ & $\begin{array}{l}\text { Early career } \\
\text { vs senior }\end{array}$ & $\begin{array}{l}\text { Mid- } \\
\text { career vs } \\
\text { senior }\end{array}$ \\
\hline Biological and biomedical sciences & $431 * * *$ & $* * *$ & $* * *$ & $* * *$ \\
\hline Business & $686 * * *$ & $* * *$ & $* * *$ & $* * *$ \\
\hline Engineering & $497 * * *$ & $* * *$ & $* * *$ & $* * *$ \\
\hline Humanities & $337 * * *$ & $* * *$ & $* * *$ & $* * *$ \\
\hline Physical and mathematical sciences & $590 * * *$ & $* * *$ & $* * *$ & $* * *$ \\
\hline Social and behavioral sciences & $1252 * * *$ & $* * *$ & $* * *$ & $* * *$ \\
\hline
\end{tabular}

${ }^{*} p<0.05 ; * * p<0.01 ; * * * p<0.001$

more in Engineering to $14 \%$ more in Business). Mid-career scholars publish more chapters than expected in all fields except Biological and Biomedical Sciences. Early career scholars publish fewer chapters than expected in all fields. Age cohort differences in the production of chapters are significant, with two exceptions: mid-career and senior scholars' rate of chapter production cannot be distinguished in Humanities nor in Physical and Mathematical Sciences (Table 10).

Similar to the pattern observed for book publications, book chapters show an overall trend in Business, Humanities, and Social and Behavioral Sciences where the number of chapters produced increases as one's academic age increases (Figs. 2, 4, and 6). In STEM fields, the number of chapters produced increases over the career trajectory, but the difference between mid-career and senior scholars is less pronounced (Figs. 1, 3, and 5). Finally, the number of chapters published overall in STEM disciplines is much lower than in the other three fields. One possible contributing factor of the increase in chapter production with the increase in academic age is that because of their experience and previous research success senior and mid-career scholars may be more likely to be invited to the conferences that produce an edited volume. The pattern exhibited by chapter publication over academic age is consistent with that seen for book publications. In both cases, there is no evidence of a peak-and-decline across career stages. Both books and chapters evince a gradual increase over academic age, unlike the more rapid increase in journal article and conference proceeding production in the early career stage in most fields. (Table 10).

We calculated the percent of scholars in each age cohort who participate in publishing for each publishing type in each field, reporting the percent of scholars with at least one publication of each type in Table 11. All fields show a lower participation in journal article publishing among senior scholars than early career or mid-career scholars, ranging from 16\% fewer participants (Business) to $6 \%$ fewer participants (Biological and Biomedical Sciences) among senior scholars than mid-career scholars. In light of the finding reported above that rates article publishing across academic age, cohorts are relatively stable across career trajectories in most fields. We conclude that a smaller proportion of the population of senior scholars is responsible for producing a greater number of journal articles. This may reflect a sort of self-selection, in which the faculty members with the strongest research programs may postpone retirement or not participate in non-research activities (e.g., university service roles) at a rate disproportionate to their less prolific colleagues. Business and Humanities show a large decline in the percent of the population that 


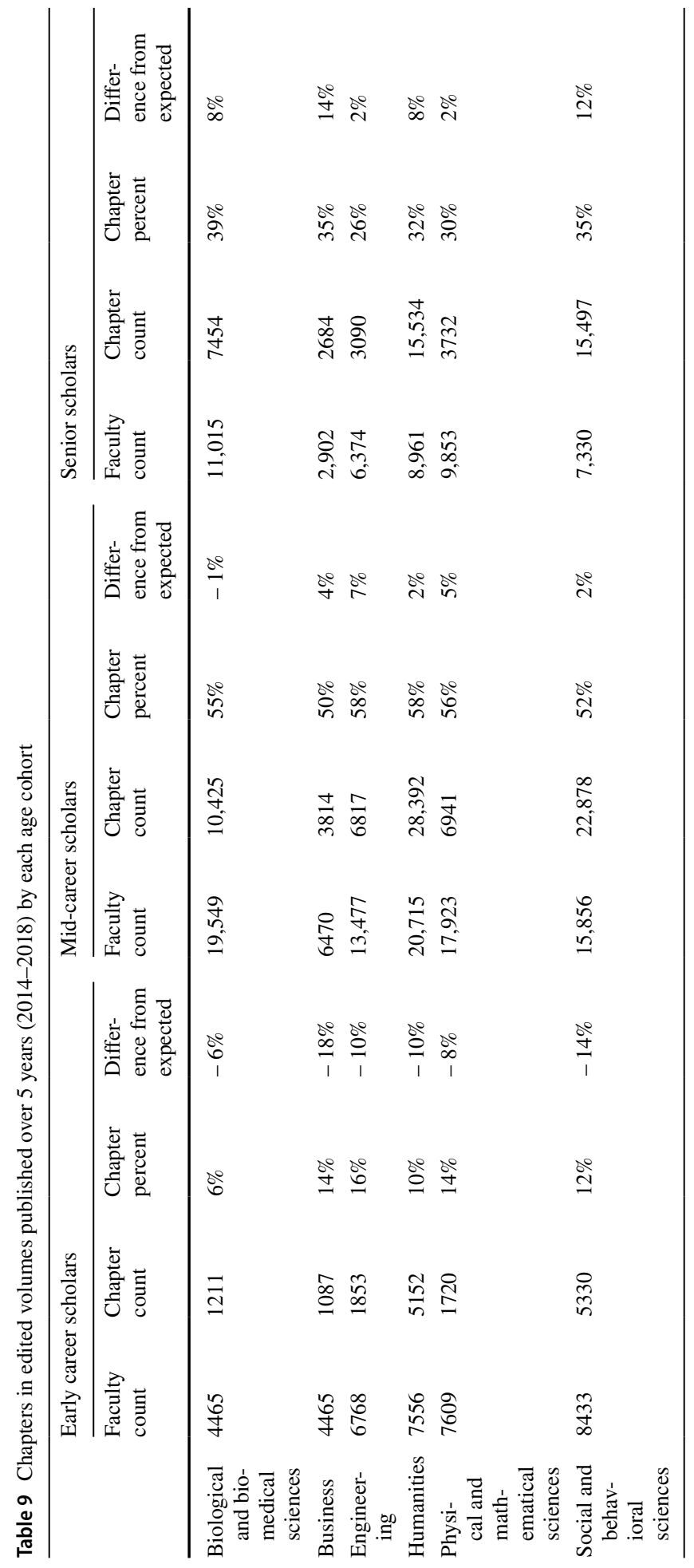


Table 10 Kruskal-Wallis and Dunn post-hoc test results comparing chapters in edited volumes published across age cohorts

\begin{tabular}{|c|c|c|c|c|}
\hline & \multirow[t]{2}{*}{ Kruskal-Wallis T } & \multicolumn{3}{|c|}{ Post-hoc comparisons } \\
\hline & & $\begin{array}{l}\text { Early career vs } \\
\text { Mid-career }\end{array}$ & $\begin{array}{l}\text { Early career } \\
\text { vs senior }\end{array}$ & $\begin{array}{l}\text { Mid- } \\
\text { career vs } \\
\text { senior }\end{array}$ \\
\hline Biological and biomedical sciences & $415^{* * *}$ & $* * *$ & $* * *$ & $* * *$ \\
\hline Business & $379 * * *$ & $* * *$ & $* * *$ & $* * *$ \\
\hline Engineering & $255^{* * *}$ & $* * *$ & $* * *$ & $* *$ \\
\hline Humanities & $704 * * *$ & $* * *$ & $* * *$ & \\
\hline Physical and mathematical sciences & $218 * * *$ & $* * *$ & $* * *$ & \\
\hline Social and behavioral sciences & $1428 * * *$ & $* * *$ & $* * *$ & $* * *$ \\
\hline
\end{tabular}

${ }^{*}, p<0.05 ; * *, p<0.01 ; * * *, p<0.001$

participates in journal article publication over career stages, dropping from $89 \%$ participation by early career scholars to $70 \%$ participation by senior scholars in Business, and from 67 to $48 \%$ in Humanities.

Differences in participation in producing conference proceedings also follows a pattern of decline between the mid-career and senior scholar career stages, but the different participation rates are generally less extreme than for journal article publication. The two fields with the greatest overall conference proceeding publication rates, Engineering and Physical and Mathematical Sciences, show declines in participation from mid-career to senior scholar career stages of 9 and $8 \%$ respectively. Unlike journal article publication, where the rate of production from mid-career to senior scholar career stages appears to be maintained by a smaller subset of highly-productive senior scholars producing more articles, Engineering and Physical and Mathematical Sciences show a decrease in the output and the rate of participation in producing conference proceedings among senior scholars.

Rates of participation in publishing books and chapters in edited volumes show an inverse pattern compared to those for journal articles and conference proceedings. With two exceptions, books and chapters show an increase in the rate of participation among senior scholars. The rate of participation in chapter publication by senior scholars in Engineering and Physical and Mathematical Sciences is slightly less than for mid-career scholars. The rate of participation in book publishing is particularly marked in Business and Social and Behavioral Sciences, which show a 9 and 10\% increase in participation from mid-career to senior scholar age cohorts, respectively. The increase in participation in the production of books and chapters by senior scholars mirrors the increase in the rate of publications of books and chapters in most fields discussed above.

In most fields and across many publication types, the right side of the plots in Figs. 1, 2, $3,4,5$ and 6 is characterized by extreme peaks in the mean publication count for many of the oldest age groups. These peaks are likely due to a combination of two factors. First, the sample size is often only one or two individuals for these age groups, as may be gleaned from the histograms at the bottom of each plot. Second, the mean calendar age of a Ph.D. recipient in the United States is 31.4 years according to the most recent Survey of Doctorates Recipients from US Universities report (2019), so scholars at the right end of the plot (academic age $40+$ years) likely have a calendar age of greater than 70 years. Faculty members actively engaged in a research program at this point in their career may have 


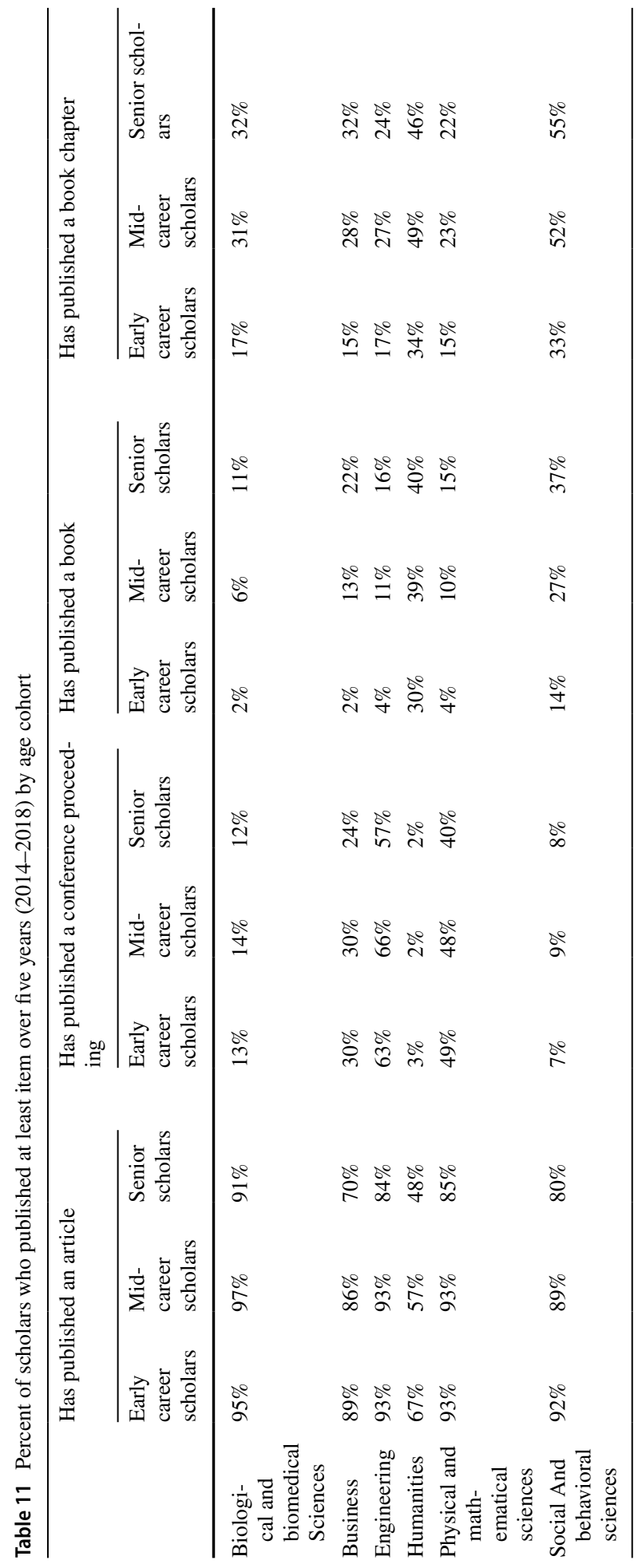


self-selected to remain in the professoriate while their less research-active colleagues may have been more likely to retire. This will skew the data toward more productive individuals at the far-right of the academic age range.

\section{Study limitations and future research directions}

Our analysis focused on a broad range of scholarly outputs, we made no attempt to explore the quality or reach of those publications across age cohorts (e.g., citation counts, altmetrics, currency with respect to the field's research trends). Citations in particular are an established, although debated, indicator of a publication's influence. While citations to and from journal articles are available from a variety of sources, citations to and from book publications (and the other publishing types we explored) are not universally available nor easy to aggregate. Nonetheless, future explorations of publishing activity by age cohort may benefit from tabulating each cohort's citation rates across publishing types. There is also evidence that open access publications are more "discoverable" than paywalled articles, ultimately garnering more citations (e.g., Piwowar et al., 2018). Different age cohorts may publish in open access venues at different rates (see discussion by Olejniczak \& Wilson, 2020) resulting in greater reach and citation counts for some age groups. Likewise, some age cohorts may be more likely to promote their research publications on social media platforms, which has been shown in some cases to increase an article's citation count (e.g., Twitter: Luc et al., 2020). Research into the demographic trends describing social media use and open access publishing proclivity across age groups may provide important context in which to interpret the reach and influence of the publication trends we identified in age cohorts.

The sample we studied is limited to a snapshot of faculty members in a single academic year. It is not clear whether the age-related patterns we identified describe a longentrenched pattern among American university professors, or only the circumstances of the narrow timeframe we studied. Longitudinal analyses would reveal not only the reliability of our results across time, but also whether age cohort-specific publishing rates are growing more disparate or converging. Our data are further limited to a single national context - the United States. Age of retirement, life expectancy, and the health of senior populations differ substantially across countries (e.g., Vandenberghe, 2020), as do tenure policies and protections (Karran, 2007), and all of these factors may lead to transnational differences in the publication prowess of senior scholars.

Our data are also limited in that we have a pooled sample of men and women, whose career paths and publication outputs are known to differ substantially in the academy. Myriad factors contribute to the likelihood of academic career advancement, among which research productivity (e.g., journal article publications and citations, patents, research grants) is perhaps the most well-studied (Ginther \& Kahn, 2006; Lundberg \& Stearns, 2019; Perna, 2007). There is no consensus why disparate rates of research productivity between men and women exist, but several potential causes have been explored. Survey data show that women often devote more time to mentoring, teaching, and service than men (Guarino \& Borden, 2017; Misra et al., 2011). Women win fewer and smaller early career research grants (Oliveira et al., 2019) and receive smaller laboratory start-up packages (Sege et al., 2015) which may have career-long consequences. Finally, women in the academy sometimes occupy positions with access to fewer resources due to childrearing and other gendered expectations (Ceci \& Williams, 2011). Future studies of age 
demographics would benefit from also incorporating gender, which is likely to influence the age-related patterns we observed in our sample.

Finally, we note that the production of research publications is not the only measure by which faculty members are evaluated. Teaching and service are also fundamental to the mission of the research university; we have made no attempt to quantify the contributions of the faculty members in our study in these areas. Fendrich (2014) commented that faculty who delay retirement "harm students, who in most cases would benefit from being taught by someone younger..." We did not explore the teaching efficacy of different age cohorts, however, we observe that the vitality of senior faculty publishing activity and their vigorous pursuit of their individual research programs suggest that classroom activities might actually benefit from their participation. Future studies of senior faculty members relative to their younger colleagues could arrive at a more holistic result than ours if they included non-research related professorial duties.

\section{Conclusions}

Despite decades of study spanning the end of mandatory retirement at American universities, the research productivity of senior scholars relative to their younger peers is not wellunderstood. This dearth of information was made clear by Zaretsky (2019), who wrote "There are no studies I could find that measure the scholarly output of academics who are 65 and over. Though there are admirable exceptions, few of my colleagues of that age show much evidence of such activity." Our study aimed to close this information gap through providing a snapshot of faculty publication activity which quantified the research outputs of scholars within a national context throughout the academic age spectrum, across multiple fields of study, and across all common modes of knowledge dissemination. We posed three research questions; our analysis of those questions can be summarized as follows:

1. The difference between the percent of a field's population that is a particular age cohort and the percent of each type of scholarly output produced by that age cohort ("the difference from expected") shows that among STEM fields senior scholars publish more journal articles than expected. In non-STEM fields (Business, Engineering, Humanities, and Social and Behavioral Sciences), senior scholars publish between 1 and 3\% fewer articles than expected. Across all fields, senior scholars publish fewer conference proceedings than expected. However, senior faculty publish many more books and book chapters than expected, sometimes as much as $25 \%$ more.

2. To explore the rate of participation by age cohorts for each scholarly output type, we calculated the percent of scholars who have produced at least one of that type of output for each field and age cohort. Senior scholars are less likely to publish journal articles overall than the other age cohorts, but those senior scholars who do publish journal articles are writing more articles per person. Conference proceeding publications are characterized by a decrease in the rate of participation and the overall quantity published by senior scholars. Conversely, senior scholar participation in the production of books and chapters increases compared to other age cohorts, mirroring the increase in the rate of publications of books and chapters in most fields.

3. Plots showing the mean number of scholarly outputs by academic age for each type of publication and for each field from zero to 65 years since terminal degree allow us to visually explore the "early peak and gradual decline" model of career publication 
trajectory. Based on our data (Figs. 1, 2, 3, 4, 5 and 6), this does not universally characterize career trajectories across fields or across publication types. Some fields show no evidence of a "peak and gradual decline" in journal article or conference proceeding publishing activity, while others reveal a gradual decline over time, particularly among conference proceeding publications. Moreover, the increased book and book chapter publishing activity of senior faculty across all fields clearly shows this model is not applicable to all types of scholarly publishing. We posit that a more accurate description of general career trajectories may be stated as a gradual change of focus away from journal articles and conference proceedings, toward book and book chapter publication.

Motivation to perform research and publish results is a complex phenomenon, influenced by factors such as peer networks, institutional support, intrinsic and economic motivations. Our analysis demonstrates that age alone does not determine overall publishing productivity, but age does influence the mode of publication. Senior scholars publish more books and book chapters than their younger colleagues, suggesting a shift towards integrating new research into the accumulated knowledge of a long career and away from fasterpaced original works such as conference proceedings. We cannot explicitly quantify the value of books and book chapters compared to journal articles and conference proceedings. As we have seen, faculty in each area of study have their own preferred publication types for dissemination of knowledge. Nonetheless, synthesizing years of knowledge production to explore new topics or re-examine old ones is an important service to one's field, one that senior scholars are especially able to perform. Available data do not permit us to address directly whether mandatory retirement would result in tenure-track faculty positions opening for younger scholars to occupy. Our analysis does, however, describe fundamental differences in the mode of publication of different age cohorts. The (hypothetical) loss of senior scholars en masse through reinstitution of a mandatory retirement age may result in the loss of knowledge dissemination in the form of books and book chapters that aggregate, summarize, and extend the development and evolution of ideas and paradigms.

Acknowledgements We thank the following individuals for thoughtful comments and suggestions: R. Berdahl, P. Lange, T. Stapleton, G. Walker, R. Wheeler, and C. Whitacre. This study was supported with data and computational resources provided by Academic Analytics, LLC. Views expressed in this article are those of the authors and do not necessarily reflect those of Academic Analytics, LLC or any other entity.

Author's contributions Both authors contributed to the study conception and design. Material preparation and data analysis was performed by AJO. The first draft of the manuscript was written by WES; all authors revised the manuscript. All authors read and approved the final manuscript.

Funding Data and computing resources were provided by Academic Analytics, LLC.

Data availability Raw data tables (anonymized to conceal individual identities) are available via OSF: https://osf.io/76urq/.

Code availability R scripts for all analyses and figures are available via OSF: https://osf.io/76urq/.

\section{Declarations}

Conflict of interest AJO and WES are paid employees of Academic Analytics, LLC. None of the authors have an equity interest in Academic Analytics, LLC. The results presented reflect the authors' opinions, and do not necessarily reflect the opinions or positions of Academic Analytics, LLC. Academic Analytics, LLC management had no oversight or involvement in the project and were not involved in preparation or review of the manuscript. All work was done as part of the respective authors' research, with no additional or external funding. 
Open Access This article is licensed under a Creative Commons Attribution 4.0 International License, which permits use, sharing, adaptation, distribution and reproduction in any medium or format, as long as you give appropriate credit to the original author(s) and the source, provide a link to the Creative Commons licence, and indicate if changes were made. The images or other third party material in this article are included in the article's Creative Commons licence, unless indicated otherwise in a credit line to the material. If material is not included in the article's Creative Commons licence and your intended use is not permitted by statutory regulation or exceeds the permitted use, you will need to obtain permission directly from the copyright holder. To view a copy of this licence, visit http://creativecommons.org/licenses/by/4.0/.

\section{References}

Abramo, G., D’Angelo, C. A., Di Costa, F., D’Angelo, C., \& Di Costa, F. (2011). Research productivity: Are higher academic ranks more productive than lower ones? Scientometrics, 88(3), 915-928. https://doi. org/10.1007/s11192-011-0426-6.

Bland, C. J., Center, B. A., Finstad, D. A., Risbey, K. R., \& Staples, J. G. (2005). A theoretical, practical, predictive model of faculty and department research productivity. Academic Medicine, 80(3). https:// journals.1ww.com/academicmedicine/Fulltext/2005/03000/A_Theoretical,_Practical,_Predictive_ Model_of.6.aspx

Bonaccorsi, A., \& Daraio, C. (2003). Age effects in scientific productivity: The case of the Italian National Research Council (CNR). Scientometrics, 58(1), 49-90. https://doi.org/10.1023/A:1025427507552.

Bonzi, S. (1992). Trends in research productivity among senior faculty. Information Processing and Management, 28(1), 111-120. https://doi.org/10.1016/0306-4573(92)90097-J.

Ceci, S.J., Williams, W.M., (2011) Understanding current causes of women's underrepresentation in science Proceedings of the National Academy of Sciences 108831573162 https://doi.org/10.1073/pnas. 1014871108

Davis, J. C., Huston, J. H., \& Patterson, D. M. (2001). The scholarly output of economists: A description of publishing patterns. Atlantic Economic Journal, 29(3), 341-349. https://doi.org/10.1007/BF02300554.

Fendrich, L. (2014, November 14). The Forever Professors. The Chronicle of Higher Education. https:// www.chronicle.com/article/Retire-Already-/149965/

Fogarty, T. J. (2004). Sustained research productivity in accounting: A study of the senior cohort. Global Perspectives on Accounting Education, 1, 31-58.

Fox, M. F. (1983). Publication productivity among scientists: A critical review. Social Studies of Science, 13(2), 285-305. https://doi.org/10.1177/030631283013002005.

Ginther, D., \& Kahn, S. (2006). Does science promote women? Evidence from academia 1973-2001. Science and Engineering Careers in the United States: An Analysis of Markets and Employment. https:// doi.org/10.3386/w12691.

Guarino, C. M., \& Borden, V. M. H. (2017). Faculty service loads and gender: Are women taking care of the academic family? Research in Higher Education, 58(6), 672-694. https://doi.org/10.1007/ s11162-017-9454-2.

Hardré, P., Beesley, A., Miller, R., \& Pace, T. (2011). Faculty motivation to do research: Across disciplines in research-extensive universities. Journal of the Professoriate, 5(1), 35-69.

Karran, T. (2007). Academic freedom in Europe: A preliminary comparative analysis. Higher Education Policy, 20(3), 289-313. https://doi.org/10.1057/palgrave.hep.8300159.

Kyvik, S. (1990). Age and scientific productivity. Differences between fields of learning. Higher Education, 19(1), 37-55. https://doi.org/10.1007/BF00142022.

Kyvik, S., \& Olsen, T. B. (2008). Does the aging of tenured academic staff affect the research performance of universities? Scientometrics, 76(3), 439-455. https://doi.org/10.1007/s11192-007-1767-z.

Levin, S. G., \& Stephan, P. E. (1989). Age and research productivity of academic scientists. Research in Higher Education, 30(5), 531-549. https://doi.org/10.1007/BF00992202.

Levin, S. G., and Stephan, P. E. (1991). Research Productivity Over the Life Cycle: Evidence for Academic Scientists. The American Economic Review, 81(1), 114-132. http://www.jstor.org/stable/2006790

Long, R., Crawford, A., White, M., \& Davis, K. (2009). Determinants of faculty research productivity in information systems: An empirical analysis of the impact of academic origin and academic affiliation. Scientometrics, 78(2), 231-260. https://doi.org/10.1007/s11192-007-1990-7.

Luc, J. G. Y., Archer, M. A., Arora, R. C., Bender, E. M., Blitz, A., Cooke, D. T., et al. (2020). Does tweeting improve citations? One-year results from the TSSMN prospective randomized trial. The Annals of Thoracic Surgery. https://doi.org/10.1016/j.athoracsur.2020.04.065. 
Lundberg, S., \& Stearns, J. (2019). Women in economics: Stalled progress. Journal of Economic Perspectives, 33(1), 3-22. https://doi.org/10.1257/jep.33.1.3.

Misra, J., Lundquist, J., Dahlberg Holmes, E., \& Agiomavritis, S. (2011). The ivory ceiling of service work. Academe, 97(1), 22-26.

National Science Foundation, \& National Center for Education Statistics. (2019). Doctorate Recipients from U.S. Universities: 2018. Alexandria, VA. https://ncses.nsf.gov/pubs/nsf20301/

NCES. (2013). Introduction to the Classification of Instructional Programs: 2010 Edition (CIP-2010). https://doi.org/10.4135/9781412957403.n289

NCES. (2019). Table 314.10. Total and full-time-equivalent (FTE) staff and FTE student/FTE staff ratios in postsecondary institutions participating in Title IV aid programs, by degree-granting status, control of institution, and primary occupation: Fall 1999, fall 2009. Digest of Education Statistics, 2019. https:// nces.ed.gov/programs/digest/d19/tables/dt19_314.10.asp

Olejniczak, A. J., \& Wilson, M. J. (2020). Who's writing Open Access (OA) articles? Characteristics of $\mathrm{OA}$ authors at $\mathrm{Ph}$. D. granting institutions in the USA. Quantitative Science Studies. https://doi.org/10. 1162/qss_a_00091.

Oliveira, D. F. M., Ma, Y., Woodruff, T. K., \& Uzzi, B. (2019). Comparison of national institutes of health grant amounts to first-time male and female principal investigators. JAMA, 321(9), 898-900. https:// doi.org/10.1001/jama.2018.21944.

Perna, L. W. (2007). Sex differences in faculty salaries: A cohort analysis. The Review of Higher Education, 24(3), 283-307. https://doi.org/10.1353/rhe.2001.0006.

Piwowar, H., Priem, J., Larivière, V., Alperin, J. P., Matthias, L., Norlander, B., et al. (2018). The state of OA: A large-scale analysis of the prevalence and impact of open access articles. PeerJ, 2018(2), 1-23. https://doi.org/10.7717/peerj.4375.

Rauber, M., \& Ursprung, H. W. (2008). Life cycle and cohort productivity in economic research: The case of Germany. German Economic Review, 9(4), 431-456. https://doi.org/10.1111/j.1468-0475.2008. 00448.x.

Sege, R., Nykiel-Bub, L., \& Selk, S. (2015). Sex differences in institutional support for junior biomedical researchers. JAMA - Journal of the American Medical Association. https://doi.org/10.1001/jama.2015. 8517.

Stroebe, W. (2010). The graying of academia will it reduce scientific productivity? The American psychologist, 65, 660-673. https://doi.org/10.1037/a0021086.

Vandenberghe, V. (2020). Differentiating retirement age to compensate for health differences. SSRN Electronic Journal. https://doi.org/10.2139/ssrn.3582657.

Way, S. F., Morgan, A. C., Clauset, A., \& Larremore, D. B. (2017). The misleading narrative of the canonical faculty productivity trajectory. Proceedings of the National Academy of Sciences of the United States of America, 114(44), E9216-E9223. https://doi.org/https://doi.org/10.1073/pnas.1702121114

Yakoboski, P. J. (2015). Creating a path forward for reluctant retirees. https://www.tiaa.org/public/pdf/ C21232_Creating_a_path_forward_for_reluctant_retirees_FINAL.pdf

Zaretsky, R. (2019, June 28). We need a mandatory retirement age for professors. Washington Post. https:// www.washingtonpost.com/opinions/we-need-a-mandatory-retirement-age-for-professors/2019/06/28/ 322dd9fa-982f-11e9-830a-21b9b36b64ad_story.html 